\title{
Exposure to non-inherited maternal antigens by breastfeeding affects antibody responsiveness
}

\author{
Henk Schonewille, ${ }^{1,2}$ Jon J. van Rood, ${ }^{3+}$ Esther P. Verduin, ${ }^{1,2,3}$ \\ Leo M.G. van de Watering,,$^{1,2}$ Geert W. Haasnoot, ${ }^{3}$ Frans H.J. Claas, ${ }^{3}$ \\ Dick Oepkes, ${ }^{4}$ Enrico Lopriore ${ }^{5}$ and Anneke Brand ${ }^{1,3}$
}

${ }^{1}$ Center for Clinical Transfusion Research, Sanquin Research, Leiden; ${ }^{2} J o n$ J van Rood Center for Clinical Transfusion Research, Sanquin-Leiden University Medical Center, Amsterdam; ${ }^{3}$ Department of Immunohematology and Blood Transfusion, Leiden University Medical Center; ${ }^{4}$ Division of Fetal Medicine, Department of Obstetrics, Leiden University Medical Center; ${ }^{5}$ Division of Neonatology, Department of Pediatrics, Leiden University Medical Center, the Netherlands

\section{ABSTRACT}

T he observation, by Ray Owen and colleagues in 1954, that D-negative women were less likely to form anti-D antibodies against their $\mathrm{D}$-positive fetus if their mother possessed the $\mathrm{D}$-antigen, was not found in all later studies. We hypothesized that breastfeeding, received by the mother, may affect her immunity against non-inherited maternal red blood cell antigens. We studied a cohort of 125 grandmother-mother-child combinations, from a follow-up study of mothers after intrauterine transfusion of the fetus for alloimmune hemolytic disease. For mismatched red blood cell antigens the mother was exposed to, whether or not antibodies were formed, we determined whether her mother, the grandmother, carried these antigens. The duration for which the mothers were breastfed was estimated by way of a questionnaire. Using multivariate logistic regression analyses, the interaction term (noninherited maternal antigen exposure by categorized breastfeeding period) showed that a longer breastfeeding period was associated with decreased alloimmunization against non-inherited maternal antigens (adjusted odds ratio 0.66; 95\% confidence interval 0.48-0.93). Sensitivity analysis with dichotomized (shorter versus longer) breastfeeding periods showed that this lower risk was reached after two months (aOR 0.22; 95\% CI 0.07-0.71) and longer duration of breastfeeding did not seem to provide additional protection. These data suggest that oral neonatal exposure to non-inherited maternal red blood cell antigens through breastfeeding for at least two months diminishes the risk of alloimmunization against these antigens when encountered later in life.

\section{Introduction}

In utero, all humans are exposed to non-inherited maternal antigens (NIMAs), however only pregnant women encounter inherited paternal antigens (IPAs). NIMAs and IPAs can involve the same antigens (Figure 1). Maternal antibodies against IPAs expressed on red blood cells (RBC) such as $\mathrm{Rh}$ and $\mathrm{K}$ antigens, can cause severe hemolytic disease of the fetus and newborn (HDFN).

In 1954, Owen and colleagues found that D-negative mothers were less likely to form anti-D against a D-positive fetus if they had previously been exposed to the D blood group as a NIMA, a phenomenon referred to as the "grandmother effect". These findings seemed in accordance with the concept of neonatal tolerance in mice, published a year earlier by Billingham and collegues. ${ }^{2}$ However, subsequent investigations did not confirm the grandmother theory. ${ }^{3-5}$ Some studies even reported that a D-negative child may develop anti-D against the D NIMA. ${ }^{67}$ As a result, the grandmother concept was almost forgotten.

Decades later, in 1988, Claas and colleagues observed that hyper-immunized dialysis patients awaiting renal allograft, formed antibodies against non-inherited
Ferrata Storti Foundation
Haematologica 2018
Volume 104(2):263-268

\section{Correspondence:}

h.schonewille@sanquin.nl

Received: June 14, 2018.

Accepted: September 11, 2018.

Pre-published: September 27, 2018.

doi:10.3324/haematol.2018.199406

Check the online version for the most updated information on this article, online supplements, and information on authorship \& disclosures: www.haematologica.org/content/104/2/263

(C)2019 Ferrata Storti Foundation

Material published in Haematologica is covered by copyright. All rights are reserved to the Ferrata Storti Foundation. Use of published material is allowed under the following terms and conditions:

https://creativecommons.org/licenses/by-nc/4.0/legalcode. Copies of published material are allowed for personal or internal use. Sharing published material for non-commercial purposes is subject to the following conditions:

https://creativecommons.org/licenses/by-nc/4.0/legalcode, sect. 3. Reproducing and sharing published material for commercial purposes is not allowed without permission in writing from the publisher. 
paternal HLA antigens (NIPAs) significantly more often than against NIMAs. ${ }^{8}$ However, a protective effect of HLA NIMAs exposure on later renal and stem cell transplant outcome was not confirmed in all further studies. ${ }^{9-11}$

Studies in mice models showed that a maximum immune tolerance to NIMA is obtained when in utero exposure to NIMA is followed by breastfeeding (BF). ${ }^{12,13}$ One study in humans showed a superior graft survival of maternal and sibling renal transplants when the recipient was breastfed. ${ }^{14}$ Other studies in humans also showed that the duration of BF was associated with autoimmune diseases later in life. . $^{15,16}$

Therefore, the controversial results on the role of exposure to NIMAs on later immunity when challenged by pregnancy, transfusion or transplantation, may - among other factors - be due to different BF habits. Breast milk contains soluble molecules such as HLA, immunoglobulins and extracellular vesicles, as well as viable cells, the latter already observed by Antoni van Leeuwenhoek in the $17^{\text {th }}$ century. ${ }^{17-19}$

Despite ante- and postnatal anti-D immunoprophylaxis since 1998, Rhesus D antibodies are still the most frequent cause of severe HDFN. We previously showed that, yearly, about 15 pregnancies complicated by anti-D, four by anti-K and one by anti-c required intra-uterine transfusions (IUT).$^{20}$ $\mathrm{RhD}$ immunoprophylaxis however hampers investigation of the effect of D NIMA exposure in utero and by BF on the anti-D response towards a D-positive child.

Severe HDFN is nowadays successfully treated with IUT. Unfortunately, such IUTs expose the mother to RBC antigens of the fetus and IUT donors, often leading to the induction of additional RBC antibodies. ${ }^{21}$

In the present study we investigated the hypothesis, that BF may affect immunity against non-inherited maternal red blood cell antigens, when encountered later in life through pregnancy or by transfusion, in a cohort of mothers whose fetuses were treated with IUT because of HDFN.

\section{Methods}

\section{Study design}

A cohort study of 125 grandmother-mother-child combinations, participating in the LOTUS (LOng Term follow Up after intrauterine transfusionS) study. In short, all women with children who were treated with IUT for HDFN from 1987-2008 were eligible. Details of the population and the methods adopted have been published previously ${ }^{22}$ (see Online Supplementary Appendix for details). All participating women were asked to invite their mothers to participate. Grandmothers were asked to complete a questionnaire on duration of breastfeeding (regardless of exclusivity). The study was approved by the ethics committee of the Leiden University Medical Center (P08.080).

\section{Data collection and intra-uterine transfusion policy}

All participants and IUT donors were typed for relevant RBC antigens (see Online Supplementary Appendix for details). The mothers were screened for RBC antibodies as previously described. ${ }^{23}$ Maternal transfusion history including date, number and donor of each IUT and number of pregnancies were collected. Over the years the transfusion policy changed with increasing degree of extended RBC antigen matching between mother and IUT donor and also procedural technique (see Online Supplementary Appendix for details). ${ }^{20,24}$

The following was determined:
1. Identification of non-D RBC antigens (C, c, E, e, K, Fy', Fy', $\mathrm{Jk}^{\mathrm{a}}, \mathrm{Jk}^{\mathrm{b}}, \mathrm{M}, \mathrm{S}$ and s) expressed by the child or IUT donor(s) but not by the mother i.e., mismatched antigens.

2. The presence or absence of maternal antibodies against each of these mismatched antigens.

3. For each mismatched antigen, whether the grandmother carried the antigen as a NIMA.

\section{Statistical analyses}

Univariate logistic regression was used to calculate odds ratio (OR) and 95\% confidence intervals (CIs). The presence of antibodies was used as the dependent variable. BF duration was analysed categorized as $0,1,2,3,4-6$ and $>6$ months and in a sensitivity analysis dichotomized ( $\leq$ or $>0,1,2,3,4$ and 6 months). Adjusted odds ratio $(\mathrm{aOR})$ was calculated in the final multivariate logistic regression model. The following variables were considered potential confounders for $\mathrm{RBC}$ antibodies: $\mathrm{ABO}$ compatibility between mother and child, maternal HLA-DRB1*15 genotype, ${ }^{25}$ number of IUTs (categorized as 1, 2, 3, 4 and $>4$ ), number of pregnancies (categorized as $\leq 2,3$ and $>3$ ), year of IUT (categorized in 5-yearblocks; 1988-93, 1994-98, 1999-03 and 2004-08) and RBC antigen immunogenicity (high: C, c, E, e and K and low: Fyª $\mathrm{Fy}^{\mathrm{b}}, \mathrm{Jk}^{\mathrm{a}}$, Jk $\mathrm{M}, \mathrm{S}$ and s antigens).

The associations between the duration of BF and the induction of antibodies were adjusted for potential confounders (i.e., $P$-values $<0.2$ in univariate analyses). To test for effect modification, two interaction terms (NIMA by months of BF and NIMA by antigen immunogenicity) were added to the model. The variables NIMA, months of BF, and the interaction term (NIMA by months of $\mathrm{BF}$ ) were forced into the model.

All statistical analyses were performed using the Statistical Package for the Social Sciences (SPSS Inc, Chicago, IL, USA). A $95 \%$ CI not overlapping the null value 1.00 for OR was regarded statistically significant.

\section{Results}

\section{Study population}

A total of 125 grandmother-mother-child pairs participated in the study. The mothers (median age at follow up, 40 years; range 24-52) gave birth to 399 children of which 143 were treated for HDFN with a total of 405 IUTs. The median birth order of the first IUT-treated child was three; there were three cases with an affected first child. The antibodies primarily responsible for HDFN were anti-D ( $n=93)$, anti-K $(n=19)$, anti-c $(n=11)$ and anti- $\mathrm{C}^{\mathrm{w}}$ and $-\mathrm{Kp}^{\mathrm{a}}$, one each (see Table 1 for additional characteristics).

A total of 549 RBC antigens - other than D - were not expressed by the mothers. For 171 of these antigens, there was no exposure by child or donor, and due to incomplete child and/or donor RBC typing, exposure was not known for 48 antigens. Consequently, analyses were restricted to the remaining 330 antigen exposures (median 3; range 1-5 per mother), of which 123 were NIMA re-exposures and 207 not previously exposed to as NIMA. These resulted in 158 antibodies, 54 (44\%) against NIMA of which six antibodies caused the HDFN, and $104(50 \%)$ against antigens not exposed to as NIMA, of which 26 caused the HDFN (Figure 2).

\section{Breastfeeding duration and antibody responses}

The median period that the 125 mothers were breastfed for was two months (range 0-12); 45 mothers were not 
breastfed, 80 mothers for a median period of three months (Table 1).

Univariate analyses revealed that antigen immunogenicity (OR 17.3; 95\% CI 10.0-29.9), number of IUTs (OR $1.22 ; 95 \%$ CI 1.04-1.43) and IUT-year (OR 0.85; 95\% CI 0.68-1.06) were associated (all $P<0.2$ ) with antibody formation. ABO compatibility, maternal HLA-DRB1*15 genotype and number of pregnancies were regarded not associated (all $P>0.5$ ) (Table 2).

Multivariate analysis showed that, high compared to low antigen immunogenicity, increasing number of IUTs and antigen exposure as NIMA compared to exposure not as NIMA were associated with an increased risk of having antibodies (aOR for the latter 3.28; 95\% CI 1.38-7.80). A longer $\mathrm{BF}$ period showed a trend towards a higher risk for antibodies (OR 1.17; 95\% CI 0.97-1.43). The interaction term (NIMA by categorized months BF) revealed that a longer $\mathrm{BF}$ period was associated with a decreased risk of antibody formation against NIMA (aOR 0.66; 95\% CI 0.48-0.93) compared to antigens not exposed to as NIMA (Table 3).

Sensitivity analyses with dichotomized periods of BF showed that BF for at least two months compared to a shorter period, and NIMA exposure were associated with an increased risk for antibodies (aOR 2.39; 95\% CI 1.125.13 and aOR 3.34; $95 \%$ CI 1.55-7.24, respectively). Again, the interaction term showed a decreased risk for antibodies against NIMA after at least two months BF (aOR $0.12 ; 95 \%$ CI $0.03-0.42$ ). These associations remained when comparing at least three months $\mathrm{BF}$ to a shorter period. Continuation of $\mathrm{BF}$ beyond three months did not seem to provide additional protection against the formation of NIMA antibodies (Table 3).

For all analyses, antigen immunogenicity and number of IUTs were associated with an increased risk for antibodies, while IUT-year and the interaction term NIMA by antigen immunogenicity were not associated with antibody risk.

\section{Discussion}

The role of exposure to RBC-NIMAs during fetal or neonatal life on later development of (non-D) RBC antibodies after re-exposure to the antigens during pregnancy as IPAs or by transfusions was investigated in 125 threegeneration families with a (grand)child with HDFN treated with IUT. In contrast to women who were breastfed for less than two months, BF for at least two months was associated with a significantly lower incidence of alloantibodies to NIMAs compared to the same antigens not previously encountered as NIMA.

The relevance of $\mathrm{BF}$ in the induction of tolerance against NIMA has mainly been studied in the context of the major histocompatibility complex (MHC) antigens in mice models. ${ }^{12,26,27}$ These studies clearly showed that a maximal immunoregulatory effect to NIMA is obtained after exposure both in utero and by $\mathrm{BF}^{12,13}$ However, the underlying mechanism(s) remain elusive, and several immunological consequences of fetal/maternal interactions have been proposed both in mice and humans. BF in mice induced Foxp $3^{+} \mathrm{CD} 25^{+} \mathrm{T}$ regulator cells potentially capable of regulating anti-maternal $\mathrm{MHC}$ immune responses. ${ }^{13,28} \mathrm{BF}$

\section{Table 1. Characteristics of the 125 mothers.}

\begin{tabular}{lc}
\hline Characteristics & N (\%)* \\
Age at follow up, median (range), years & $40(24-52)$ \\
BF duration in months, median (range) & $2(0-12)$ \\
No breastfeeding & $45(36)$ \\
One month & $17(14)$ \\
Two months & $15(12)$ \\
Three months & $17(14)$ \\
Four to six months & $18(14)$ \\
More than six months & $13(10)$ \\
\hline Birth order of first IUT treated child, median (range) & $3(1-7)$ \\
Number of IUTs, median (range) & $3(1-10)$ \\
\hline Maternal-fetal major ABO compatibility - N/N tested (\%) $101 / 112(90)$ \\
HLA-DRB1*15 positive & $38(30)$ \\
\hline Antibody causing HDFN: & \\
Anti-D & $93(74)$ \\
Anti-K & $19(15)$ \\
Anti-c & $11(9)$ \\
Anti-Kpa and -Cw & $2(2)$ \\
\hline
\end{tabular}

BF: breastfeeding; IUT: intra-uterine transfusion; HDFN: hemolytic disease of the fetus and newborn. *: Data presented as number (\%) of women unless stated otherwise.

Table 2. Variables associated with RBC antibody formation after mismatched antigen exposures, univariate analysis.

\begin{tabular}{|c|c|c|c|}
\hline Variables & OR & $95 \%$ Cl & $P$ \\
\hline RBC antigen immunogenicity (low** $[$ non $\mathrm{Rh}, \mathrm{K}]$ vs. high $[\mathrm{Rh}, \mathrm{K}]$ ) & 17.3 & $10.0-29.9$ & $<0.001$ \\
\hline Number of IUTs $(1,2,3,4$ and $>4)$ & 1.22 & $1.04-1.43$ & 0.014 \\
\hline IUT year (5-year blocks) & 0.85 & $0.68-1.06$ & 0.148 \\
\hline ABO compatibility** versus incompatibility & 1.26 & $0.62-2.57$ & 0.531 \\
\hline HLA-DRB1*15 genotype absent** versus present & 1.10 & $0.69-1.75$ & 0.689 \\
\hline Number of pregnancies $(\leq 2,3$ and $>3)$ & 0.98 & $0.75-1.27$ & 0.877 \\
\hline Exposure not as a NIMA** vs. NIMA re-exposure & 0.78 & $0.50-1.21$ & 0.265 \\
\hline Breastfeeding months $(0,1,2,3,4-6$ and $>6)$ & 0.98 & $0.87-1.10$ & 0.721 \\
\hline Antibodies after NIMA-mismatched exposures & 1.08 & $0.93-1.25$ & 0.320 \\
\hline Antibodies after NIMA-matched exposures & 0.82 & $0.67-1.01$ & 0.062 \\
\hline
\end{tabular}

RBC: red blood cell; OR: odds ratio; CI: confidence interval; IUT: intra-uterine transfusion; NIMA: non-inherited maternal antigen; [non Rh, K]: Fya, Fyb,Jka, Jkb, M,S and s antigens $[\mathrm{Rh}, \mathrm{K}]: \mathrm{C}, \mathrm{c}, \mathrm{E}, \mathrm{e}$ and $\mathrm{K}$ antigens; **: reference. 


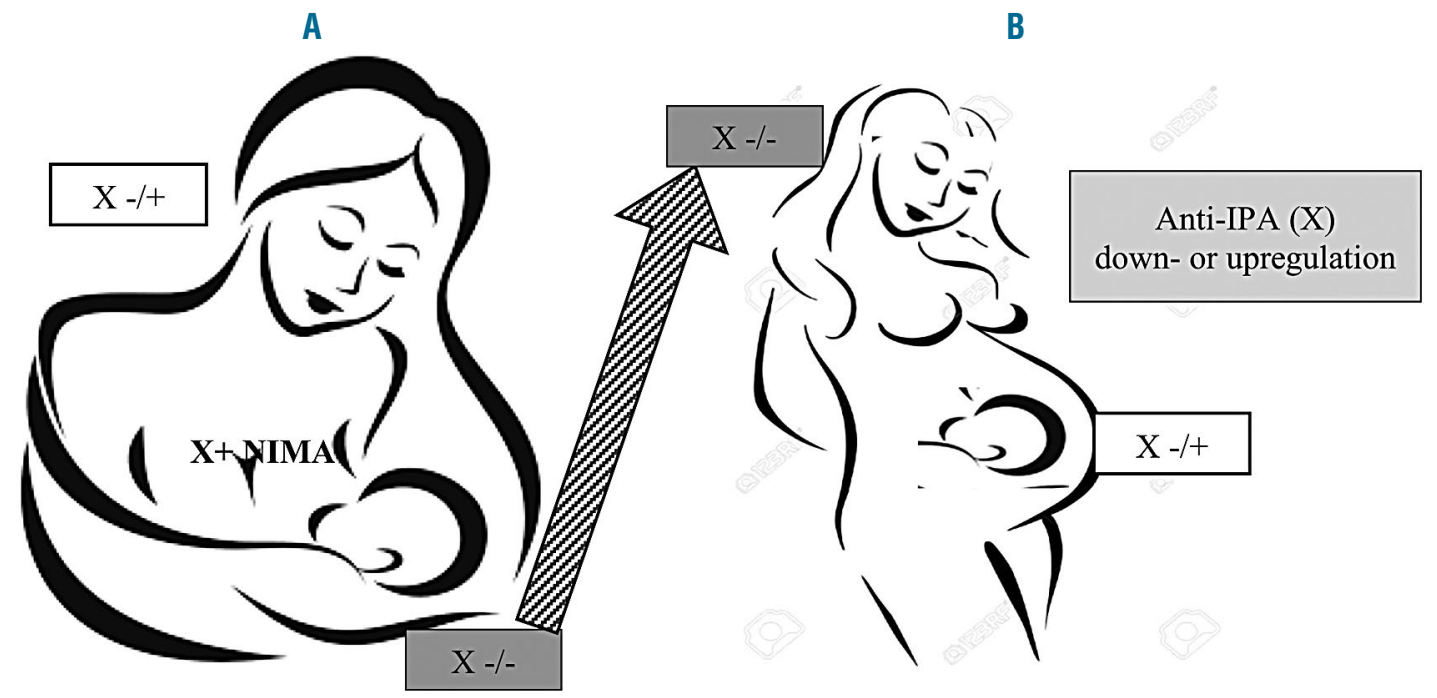

C

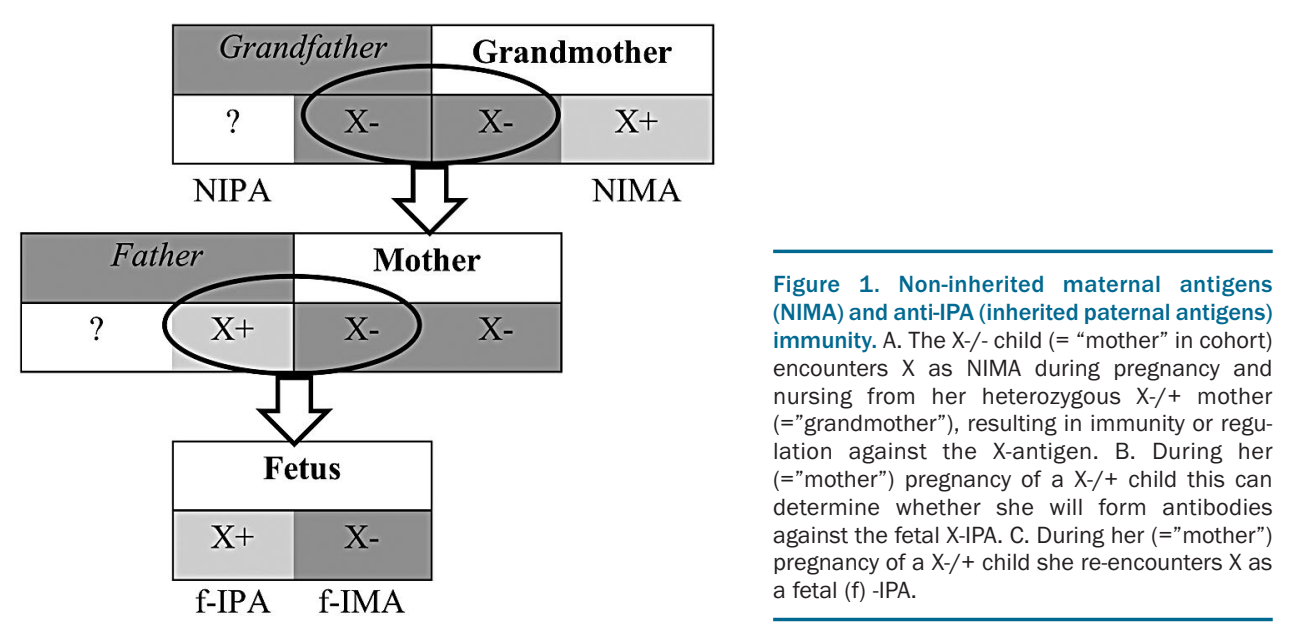

implies extended exposure to soluble and cellular maternal antigens and, in addition, extracellular vescicles (EVs) which can exert several immune effects. EVs are derived from a variety of cells including RBC, and several clinically relevant Rhesus, Kell, Duffy and Kidd blood group antigens are expressed. ${ }^{29,30}$ Erythrocyte derived EVs have immunomodulating properties. ${ }^{31} \mathrm{Up}$ to 6 months after delivery, human colostrum and breast milk contains exosomes capable of increasing Foxp $3^{+} \mathrm{CD} 4^{+} \mathrm{CD} 25^{+}$allospecific $T$ regulator cells in vitro. ${ }^{19}$ In the postnatal period, when the newborn is developing immunity against environmental threats, prolonged exposure to the maternal antigens may be perceived as auto-antigens requiring regulation. Moreover, oral exposure to antigens and antigen-antibody complexes was reported to induce regulation in neonates as well as in adults. ${ }^{32,33}$ In D-sensitized women pregnant of a subsequent D-positive child, oral administration of Dantigen inhibited an expected boost in anti-D titer. ${ }^{34}$ Finally, breast milk provides an additional source of viable maternal cells that may increase maternal microchimerism, which is considered a driving force of regulation leading to maintenance of tolerance for NIMAs. ${ }^{18,35,36}$

A different history of maternal BF may explain the discrepancy of finding a grandmother effect in various studies. Until manufactured baby milk became available, BF was part of our immunological education. Several, also cultural aspects, such as wealth and women's emancipation, often replaced BF by cow milk. This may however have consequences that are still unknown. Another aspect of $\mathrm{BF}$ is the transmission of maternal cells which seem to play a role in immunity against malignant diseases in the child as shown by Amatay and colleagues, based on a meta-analysis suggesting that BF may strengthen antileukemic immunity in progeny. ${ }^{37}$

Our observations on the effect of oral exposure to NIMAs by BF may not just explain the historical controversies regarding the grandmother theory. Why only a minority of individuals form RBC alloantibodies after pregnancy and/or blood transfusions (responders), while 
Table 3. Variables associated with red blood cell antibody formation after mismatched antigen exposures, by categorized and dichotomized breastfeeding periods, multivariate analysis.*

\begin{tabular}{|c|c|c|c|c|c|c|}
\hline \multirow[t]{2}{*}{ BF duration } & \multicolumn{2}{|c|}{ Breastfeeding } & \multicolumn{2}{|c|}{ NIMA exposure** } & \multicolumn{2}{|c|}{ NIMA by months BF } \\
\hline & $\mathrm{aOR}$ & $95 \%$ CI & $\mathrm{aOR}$ & $95 \%$ CI & $\mathrm{aOR}$ & $95 \%$ CI \\
\hline \multicolumn{7}{|l|}{ Categorized } \\
\hline $0,1,2,3,4-6,>6$ & 1.17 & $0.97-1.43$ & 3.28 & $1.38-7.80$ & 0.66 & $0.48-0.93$ \\
\hline \multicolumn{7}{|l|}{ Dichotomized } \\
\hline $0 v s_{s}>0$ & 1.11 & $0.54-2.26$ & 1.81 & $0.68-4.79$ & 0.77 & $0.23-2.53$ \\
\hline$\leq 1 v S .>1$ & 1.15 & $0.56-2.33$ & 1.78 & $0.71-4.41$ & 0.78 & $0.24-2.48$ \\
\hline$\leq 2$ vs. $>2$ & 2.39 & $1.12-5.13$ & 3.34 & $1.55-7.24$ & 0.12 & $0.03-0.42$ \\
\hline$\leq 3$ vs $>3$ & 1.95 & $0.83-4.59$ & 2.49 & $1.23-5.06$ & 0.41 & $0.03-0.59$ \\
\hline$\leq 4$ vs. $>4$ & 1.34 & $0.53-3.43$ & 1.77 & $0.92-3.39$ & 0.37 & $0.07-1.98$ \\
\hline$\leq 6$ us. $>6$ & 1.08 & $0.35-3.32$ & 1.55 & $0.83-2.92$ & 0.86 & $0.13-5.61$ \\
\hline$<2$ vs. $>3$ & 2.37 & $0.93-6.05$ & 3.57 & $1.47-8.70$ & 0.11 & $0.02-0.51$ \\
\hline 2 and 3 vs. $>3$ & 1.11 & $0.41-2.96$ & 1.15 & $0.36-3.69$ & 0.35 & $0.07-1.80$ \\
\hline
\end{tabular}

*The complete table 3 , including results from the variables, Immunogenicity, Number of IUTs, Year of IUT and the interaction term NIMA by Immunogenicity are in the Online Supplementary Appendix. BF: breastfeeding; NIMA: non-inherited maternal antigen; aOR: adjusted odds ratio; CI: confidence interval; **The reference is incidence of antibodies after exposure not as a NIMA.

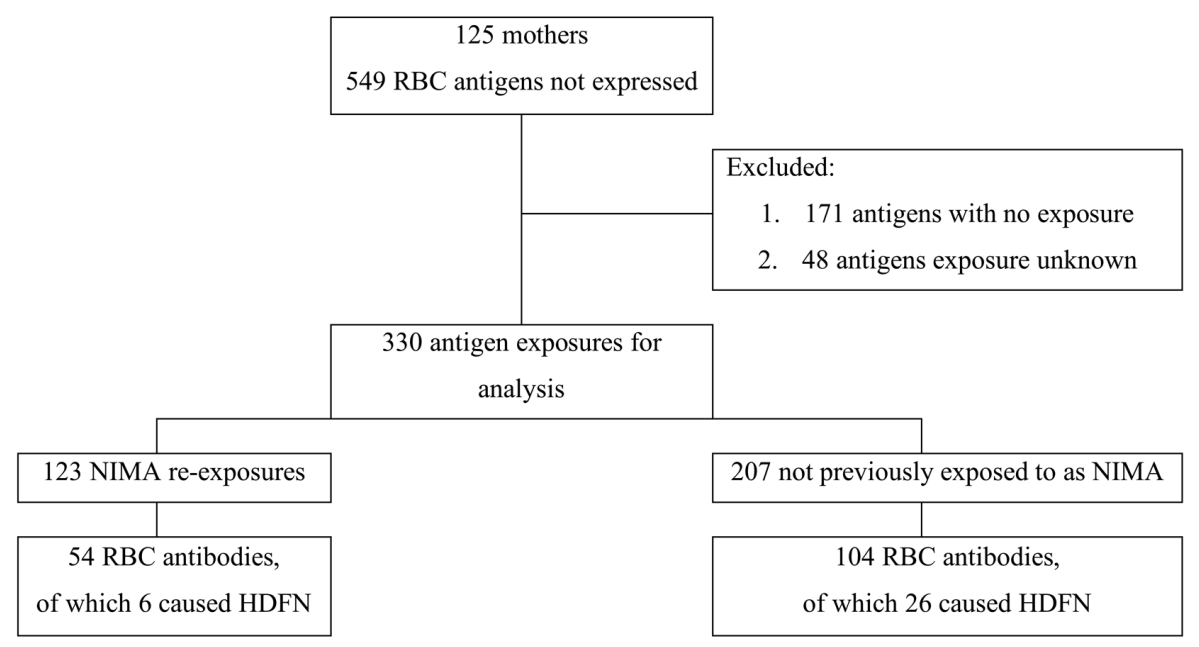

Figure 2. Study flowchart of 125 mothers exposed to 330 non-D RBC antigens and antibody response. RBC: red blood cell; NIMA: non-inherited maternal antigen; HDFN: hemolytic disease of the fetus and newborn.

others do not, despite multiple exposures to mismatched $\mathrm{RBC}$ antigens (nonresponders), has yet to be unravelled and considered to be multifactorial. Factors such as antigen immunogenicity and dose, route of exposure, race, age, co-existence of inflammation during RBC antigen exposure, genetic factors (such as HLA and immunoregulatory gene polymorphisms), and medical (immunosuppressive) conditions have all been reported to enhance or ameliorate RBC alloantibody formation. ${ }^{38-42}$ The duration of exposure to NIMA by BF adds a new aspect to this already complex question.

\section{Limitations}

Firstly, our study cohort - similar to the HLA immunized cohort on the renal transplant waiting list, mentioned before $^{8}$ - consisted of highly immunized individuals, already possessing at inclusion at least one strong $\mathrm{RBC}$ antibody causing HDFN. We previously showed that once individuals produced an RBC antibody, there is over a $20 \%$ risk of forming additional antibodies upon subsequent exposures. ${ }^{21,43}$ The results in these extensively allo- exposed young women, of which $80 \%$ formed antibodies against multiple RBC antigens after delivery, may not be generalizable for first RBC antigen encounter and for immune-compromised patients. Secondly, unidentified or unknown antigen exposures that had not resulted in RBC antibodies may have been missed; however, it is likely that these were equally distributed in the distinct BF periods. Thirdly, Owen and colleagues evaluated anti-D formation in relation to the D-NIMA. As a result of $\mathrm{RhD}$ immunoprophylaxis, we could not repeat Owen's design, however we did find support for a grandmother effect to non-D NIMAs after oral exposure by more than two months BF. Fourthly, the duration of BF was assessed through a questionnaire. BF was given decades before this study, and memory may not be exactly accurate. Lastly, in agreement with Owen, our study is hypothesis-generating and needs corroboration before drawing any definitive conclusion.

In conclusion, in women with HDFN-affected children, prolonged oral exposure to non-D NIMA by BF was associated with a significantly lower incidence of antibody production when later challenged to these NIMAs com- 
pared to exposure to the same antigens not previously exposed to as NIMAs.

Ray Owen and colleagues concluded their 1954 publication on the grandmother theory with these words: "Presentation of this hypothesis here, on the basis of admittedly limited data, is justified by the hope that others in a position to test it will be encouraged to do so."

\section{Acknowledgments}

The authors express their special thanks to all families who participated in the LOTUS study.

The LOTUS study group is a consortium of Sanquin and the Leiden University Medical Center departments of Immunohematology and Blood transfusion, Obstetrics and Neonatology.

\section{References}

1. Owen RD, Wood HR, Foord AG, Sturgeon P, Baldwin LG. Evidence for actively acquired tolerance to $\mathrm{Rh}$ antigens. Proc Natl Acad Sci USA. 1954:40(6):420-424

2. Billingham RE, Brent L, Medawar PB. Actively acquired tolerance of foreign cells. Nature. 1953;172(4379):603-606.

3. Booth RD, Dunsford J, Grant J, Murray S. Haemolytic disease in first-born infants. Brit Med J. 1953;2(4826):41-42.

4. Ward HK, Walsh RJ, Kooptzoff O. Rh antigens and immunological tolerance. Nature. 1957:179(4574):1352-1353

5. Mayeda K. The self-marker concept as applied to the Rh blood group system. Am J Hum Genet. 1962:14(3):281-289.

6. Taylor JF. Sensitization of Rh-negative daughters by their Rh-positive mothers. N Engl J Med. 1967;276(10):547-551.

7. Hattevig $G$, Jonsson $M$, Kjellman $B$, Khellman $\mathrm{H}$, Messeter L, Tibblin E. Screening of Rh-antibodies in Rh-negative female infants with Rh-positive mothers. Acta Paediatr Scand. 1981;70(4):541-545

8. Claas FH, Gijbels Y, van der Velden-de Munck J, van Rood JJ. Induction of B cell unresponsiveness to noninherited maternal HLA antigen during fetal life. Science. 1988;241(4874):1815-1817.

9. Burlingham WJ, Grailer AP, Heisey DM, et al. The effect of tolerance to noninherited maternal HLA antigens on the survival of renal transplants from sibling donors. $N$ Engl J Med. 1998:339(23):1657-1664.

10. Panajotopoulos N, Ianhez LE, Neumann J, Sabbaga E, Kalil J. Immunological tolerance in human transplantation. The possible existence of a maternal effect. Transplantation. 1990;50(3):443-445.

11. Pohanka E, Cohen N, Colombe BW, Lou C, Salvatierra O Jr, Garovoy MR. Non-inherited maternal HLA antigens and protection against sensitization. Lancet. 1990;336 (8722):1025-1028.

12. Andrassy J, Kusaka S, Jankowska-Gan E, et al. Tolerance to noninherited maternal MHC antigens in mice. J Immunol. 2003;171(10): 5554-5561

13. Aoyama K, Koyama M, Matsuoka K, et al. Improved outcome of allogeneic bone marrow transplantation due to breastfeedinginduced tolerance to maternal antigens. Blood. 2009;113(8):1829-1833.

14. Kois WE, Campbell DA Jr, Lorber MI, Sweeton JC, Dafoe DC. Influence of breast feeding on subsequent reactivity to a related renal allograft. J Surg Res. 1984;37(2):89-93.

15. Kindgren E, Fredrikson M, Ludvigsson J. Early feeding and risk of juvenile idiopathic arthritis: a case control study in a prospective birth cohort. Pediatr Rheumatol 2017;15(1):46.

16. Conradi S, Malzahn U, Paul F, et al. Breastfeeding is associated with lower risk for multiple sclerosis. Mult Scler. 2013;19(5):553-558
17. Van Leeuwenhoek A. Arcana naturae detecta delphis batavorum. Apud Henricum a Krooneveld 1695

18. Hassiotou F, Beltran A, Chetwynd E, et al. Breastmilk is a novel source of stem cells with multilineage differentiation potential. Stem Cells. 2012;30(10):2164-2174

19. Admyre C, Johansson SM, Qazi KR, et al. Exosomes with immune modulatory features are present in human breast milk. J Immunol. 2007;179(3):1969-1978.

20. Schonewille H, Prinsen-Zander KJ, Reijnart $M$, et al. Extended matched intrauterine transfusions reduce maternal Duffy, Kidd, and $\mathrm{S}$ antibody formation. Transfusion. 2015:55(12):2912-2919.

21. Schonewille $\mathrm{H}$, Klumper FJ, van de Watering LM, Kanhai HH, Brand A. High additional maternal red cell alloimmunization after Rhesus- and K-matched intrauterine intravascular transfusions for hemolytic disease of the fetus. Am J Obstet Gynecol. 2007;196(2):e143-146

22. Verduin EP, Lindenburg IT, Smits-Wintiens VE, et al. LOng-Term follow up after intraUterine transfusionS: the LOTUS study. BMC Pregnancy Childbirth. 2010;10:77.

23. Verduin EP, Schonewille H, Brand A, et al. High anti-HLA response in women exposed to intrauterine transfusions for severe alloimmune haemolytic disease is associated with mother-child HLA triplet mismatches, high anti-D titer, and new red blood cell antibody formation. Transfusion. 2013;53(5):939-947.

24. Zwiers C, Lindenburg ITM, Klumper FJ, de Haas M, Oepkes D, Van Kamp IL. Complications of intrauterine intravascular blood transfusion: lessons learned after 1678 procedures. Ultrasound Obstet Gynecol. 2017;50(2):180-186

25. Verduin EP, Brand A, van de Watering LM, et al. The HLA-DRB1*15 phenotype is associated with multiple red blood cell and HLA antibody responsiveness. Transfusion. 2016;56(7):1849-1856

26. Molitor-Dart ML, Andrassy J, Haynes LD, Burlingham WJ. Tolerance induction or sensitization in mice exposed to noninherited maternal antigen (NIMA). Am J Transplant. 2008:8(11):2307-2315.

27. Opiela SJ, Levy RB, Adkins B. Murine neonates develop vigorous in vivo cytotoxic and Th1/Th2 responses upon exposure to low doses of NIMA-like alloantigens. Blood. 2008;112(4):1530-1538

28. Matsuoka K, Ichinohe T, Hashimoto D, Asakura S, Tanimoto M, Teshima T. Fetal tolerance to maternal antigens improves the outcome of allogeneic bone marrow transplantation by a CD4+ CD25+ T-cell-dependent mechanism. Blood. 2006;107(1):404 409.

29. Jaime-Pérez JC, Gómez-Almaguer D Immunoreactivity of common red blood cell antigens in cytoskeleton-free red blood cell microvesicles. Arch Med Res. 2000;30(2): 169-171

30. Canellini G, Rubin O, Delobel J, Crettaz D,
Lion N, Tissot JD. Red blood cell microparticles and blood group antigens: an analysis by flow cytometry. Blood Transfus. 2012;10 (suppl 2):s39-45

31. Sadallah S, Eken C, Schifferli JA Erythrocyte-derived ectosomes have immunosuppressive properties. J Leukoc Biol. 2008;84(5):1316-1325.

32. Hostmann A, Meyer T, Maul J, et al Preexisting antigen-specific immune responses are modulated by oral $\mathrm{KLH}$ feeding in humans. Eur J Immunol. 2015;45(7): 1991-1996.

33. Mosconi E, Rekima A, Seitz-Polski B, et al Breast milk immune complexes are potent inducers of oral tolerance in neonates and prevent asthma development. Mucosal Immunol. 2010;3(5):461-474.

34. Bierme SJ, Blanc M, Abbal M, Fournie A. Oral Rh treatment for severely immunised mothers. Lancet. 1979;1(8116):604-605.

35. Zhou L, Yoshimura Y, Huang Y, et al. Two independent pathways of maternal cell transmission to offspring: through placenta during pregnancy and by breast-feeding after birth. Immunology. 2000;101(4):570580.

36. Molitor ML, Haynes LD, Jankowska-Gan E, Mulder A, Burlingham WJ. HLA class I noninherited maternal antigens in cord blood and breast milk. Hum Immunol. 2004;65(3):231-239.

37. Amitay EL, Keinan-Boker L. Breastfeeding and childhood leukemia incidence: A metaanalysis and systematic review. JAMA Pediatr. 2015;169(6):e151025.

38. Karafin MS, Westlake M, Hauser RG, et al NHLBI Recipient Epidemiology and Donor Evaluation Study-III (REDS-III).Risk factors for red blood cell alloimmunization in the Recipient Epidemiology and Donor Evaluation Study (REDS-III) database. Br J Haematol. 2018;181(5):672-681.

39. Schonewille $\mathrm{H}$, Doxiadis II, Levering $\mathrm{WH}$ Roelen DL, Claas FH, Brand A. HLA-DRB1 associations in individuals with single and multiple clinically relevant red blood cell antibodies. Transfusion. 2014;54(8):1971-1980.

40. Tatari-Calderone Z, Tamouza R, Le Bouder GP, et al. The association of CD81 polymorphisms with alloimmunization in sickle cell disease. Clin Dev Immunol. 2013;2013: 937846

41. Sippert EÂ, Visentainer JE, Alves HV, et al Red blood cell alloimmunization in patients with sickle cell disease: correlation with HLA and cytokine gene polymorphisms. Transfusion. 2017:57(2):379-389

42. Meinderts SM, Sins JWR, Fijnvandraat K, et al. Non-classical FCGR2C haplotype is associated with protection from red blood cell allo-immunization in sickle cell disease. Blood. 2017;130(19):2121-2130

43. Schonewille $\mathrm{H}$, van de Watering LMG, Brand A. Additional RBC alloantibodies after blood transfusion in a non-hematological alloimmunized patient cohort. Is it time to take precautionary measures? Transfusion. 2006;46(4):630-635. 